Research Articles

\title{
Randomized Controlled Trial of Tranexamic Acid's Effect on Bleeding Length: A Study on DMPA Users with Abnormal Uterine Bleeding Who Receive Low-Dose Oral Contraceptive Pill
}

\author{
Rabiah Adawiyah*, Inu Mulyantoro, Julian Dewantiningrum, Noor Pramono
}

Obstetrics and Gynecology Department, Faculty of Medicine, Diponegoro University,dr. Kariadi Hospital, Semarang, Indonesia

\section{Article Info}

History:

Received: 07 July 2019

Accepted: 17 March 2020

Available: 30 April 2020

\begin{abstract}
Background: Contraceptive injection is the most common contraception used in Indonesia. Among the contraceptive injections, depomedroxy progesterone acetate (DMPA) is the most effective method with a pregnancy rate of 0,3 pregnancy in 100 women annually. Abnormal uterine bleeding (AUB) is a common side effect occurred in DMPA users which leads to the discontinuation of contraception. Tranexamic acid (TXA) can be used as an alternative therapy for AUB due to DMPA injection, if bleeding still occurs after low dose OCP therapy.

Objective: To explore the effect of TXA on bleeding length for DMPA users with AUB who receive low dose Oral Contraceptive Pills(OCP).

Methods: We performed a double-blind randomized control trial between two groups to investigate the effect of TXA in managing AUB in DMPA users who receive low dose OCP. This study was performed in dr. Kariadi Hospital Semarang, Indonesia. Forty-four subjects were divided into two groups, equally. Group 1 received $250 \mathrm{mg}$ TXA four times a day for 5 days and OCP once a day for 28 days, while Group 2 received placebo four times a day for 5 days and OCP once a day for 28 days. Both groups were evaluated for bleeding length during treatment and were analyzed using Mann Whitney.

Results: The mean bleeding length was $5.2 \pm 3.62$ days and 9.2 \pm 6.16 days in group 1 and 2 respectively. These bleeding lengths were significantly different between both groups $(\mathrm{p}=0.018)$. The percentage of subjects in whom bleeding was stopped during the first week after initial treatment was significantly higher in group 1 than group 2 (77.3\% VS $45.5 \%$, p<0.050).

Conclusion: TXA significantly reduced the bleeding length in DMPA users who use OCP. TXA can be used as alternative therapy to enhance the OCP effectivity for AUB due to DMPA.
\end{abstract}

Keywords: OCP; tranexamic acid; AUB

Permalink/ DOI: https://doi.org/10.14710/jbtr.v6i1.4450

\section{INTRODUCTION}

Contraception program in countries with fastgrowing population will decrease maternal mortality and neonatal mortality leading to the achievement of Sustainable Developmental Goals (SDG). ${ }^{1,2,3}$ In fact, there are $9 \%$ of unmet need (reproductive women who want to delay pregnancy or do not want to be pregnant anymore but do not use contraception) with one of the main reason was the side effects of contraception, such as Abnormal Uterine Bleeding (AUB). ${ }^{4,5}$ Contraceptive injection is the most common contraception used in
Indonesia which about $32 \% .^{5}$ Among the contraceptive injections, depo medroxyprogesterone acetate (DMPA) is the most effective one. Unfortunately, $90 \%$ of DMPA users experience AUB, and this bleeding will lead to the discontinuation of the contraception. ${ }^{6}$

\footnotetext{
* Corresponding author:

E-mail: rabiahadawiyah732@gmail.com

(Rabiah Adawiyah)
} 
Abnormal uterine bleeding due to DMPA is categorized in AUB-I (Iatrogenic) according to International Federation of Gynecology and Obstetrics (FIGO) classification. ${ }^{7}$ The mechanism of the bleeding related to use of DMPA is not fully understood. The proposed mechanism is continuous endometrial exposure to a constant dose of progesterone. The activity of matrix metalloproteinase-9 (MMP-9) increase in DMPA users, while the activity of Tissue Inhibitory Metalloproteinase (TIMP) reduced. These events lead to weakening the supportive tissue around the vascular under the epithelial, hence the endometrial layer becomes fragile and the vascular is damaged. Therefore, bleeding occurs. ${ }^{8,9,10}$

Intervention that effectively controlled AUB will improve the continuation rate..$^{8,11,12}$ The strategies for managing the bleeding that disturb DMPA users include combined oral contraceptive pills (OCP). ${ }^{11}$ If AUB still occurred while the patients is on OCPs, the next step is increasing the dosage of estrogen in OCP. OCP itself can reduce the bleeding about $34.9 \%$. The highest success rate to reduce AUB is insertion of Levonorgestrel Intrauterine Device (LNG-IUD) which can reduce the bleeding about $87 \%$, but the weakness of this IUD are low acceptance and high cost, so clinician frequently add tranexamic acid (TXA) in DMPA users with AUB ${ }^{13}$ Endometrial fibrinolytic enzymes have important role in menstrual bleeding hemostatic, in AUB, plasmin activity and plasminogen activator increase, that will lead to the bleeding. ${ }^{14,1}$ TXA is widely known as antifibrinolytic, ${ }^{15}$ and commonly used to reduce heavy menstrual bleeding by reducing fibrin degradation in endometrial layer, which is expected to increase the effectivity of low dose OCP in managing the bleeding to improve the continuation rate of DMPA. Unfortunately, we do not have data about the effect of TXA and OCP on bleeding length due to DMPA. So the aim of this study is to explore the effect of TXA on bleeding length for DMPA users who receive low dose OCP.

\section{MATERIALS AND METHOD}

This double-blind randomized controlled trial was conducted in dr. Kariadi General Hospital in Semarang, Indonesia from October 2016 to August 2017. The participants were women using DMPA with AUB.

Inclusion criteria were being a new DMPA users, age 20-45 years old, and a normal pelvic examination. Exclusion criteria were applied if the subjects had a gynecological disease that causes abnormal uterine bleeding, had a medical disease with bleeding tendency, allergic to TXA, contraindication to OCP and TXA and had a history of liver impairment and renal insufficiency.

AUB in this study was defined as bleeding or spotting for eight or more days in a month, which is appropriate with FIGO classification for prolonged AUB (which is more than 8 days). ${ }^{7}$ Before the study started, each subject was asked to read and sign informed consent. Written informed consent was obtained from the participants of the study and patients have a right and privacy to join the study and they can resign from the study anytime they want. We informed that OCP only is good enough in reducing the bleeding for about $34.9 \%$, and this study aim to know whether TXA can enhance the effect of OCP in reducing bleeding length in DMPA users. TXA is widely known as antifibrinolytic, and commonly used to reduce heavy menstrual bleeding by reducing fibrin degradation in endometrial layer, which is expected to increase the effectivity of low dose OCP in managing the bleeding to improve the continuation rate of DMPA.

Forty-four subjects in this study were divided with simple randomization into two groups, twenty-two subjects each. The first group received low dose OCP and TXA, while the second group received placebo and low dose OCP. The drugs for both groups were packaged in same colored capsules, we also asked people outside of author and co-author to choose a closed envelope containing which group the subjects would be assigned to. Both authors and subjects were not aware of the administered drugs.

Written informed consent was obtained from the participants of the study and patients have a right and privacy to join the study and they can resign from the study anytime they want. We informed that OCP only is good enough in reducing the bleeding for about $34.9 \%$, and this study aim to know whether TXA can enhance the effect of OCP in reducing bleeding length in DMPA users.

The dose of TXA was $250 \mathrm{mg}$. Both TXA and placebo were administered four times a day for 5 day (as previous study by Senthong A and Taneepanichskul), although according to our local consensus the recommended dose of TXA for AUB is $1 \mathrm{~g}$ three times daily. Both groups also received low dose OCP, containing $30 \mathrm{mcg}$ ethinylestradiol and $150 \mathrm{mg}$ levonorgestrel (Microgynon ${ }^{\circledR}$ ), Bayer Schering Pharma, Berlin, Germany) to be administered once a day for 28 days. Each subject received a card for documenting vaginal bleeding and side effect during the medication. The obtained data were analyzed. The difference of bleeding length between the two groups during the treatment was analyzed by a non-paired t-test for normal data distribution or Mann Whitney test for not normal data distribution. Data were analyzed by SPSS for windows version 15.0 (SPSS Inc, USA). The data were considered significant if $\mathrm{p}$ value $<0.05$.

This study was approved by the Ethics Committee of Faculty of Medicine Diponegoro University and dr. Kariadi Hospital number 936/EC/FK-RSDK/IX/2016 and was conducted according to the Declaration of Helsinki.

\section{RESULTS}

There were 44 subjects; which then randomly assigned to 2 groups of treatment. Group 1 consist of 22 women who received once-daily OCP for 28 days and TXA $250 \mathrm{mg}$, four-time daily for five days, and group 2 consist of 22 women who received once daily OCP for 28 days and placebo four-time daily for five days. Until the end of the study no subject resigned, all of the 44 women fill the menstrual card as shown in the Consort Diagram of Figure 1.

Table 1 showed characteristics of subjects, there was no significant difference of those characteristics (age, BMI, and number of previous pregnancies) between both groups. Therefore, those characteristics did not affect the study results. 


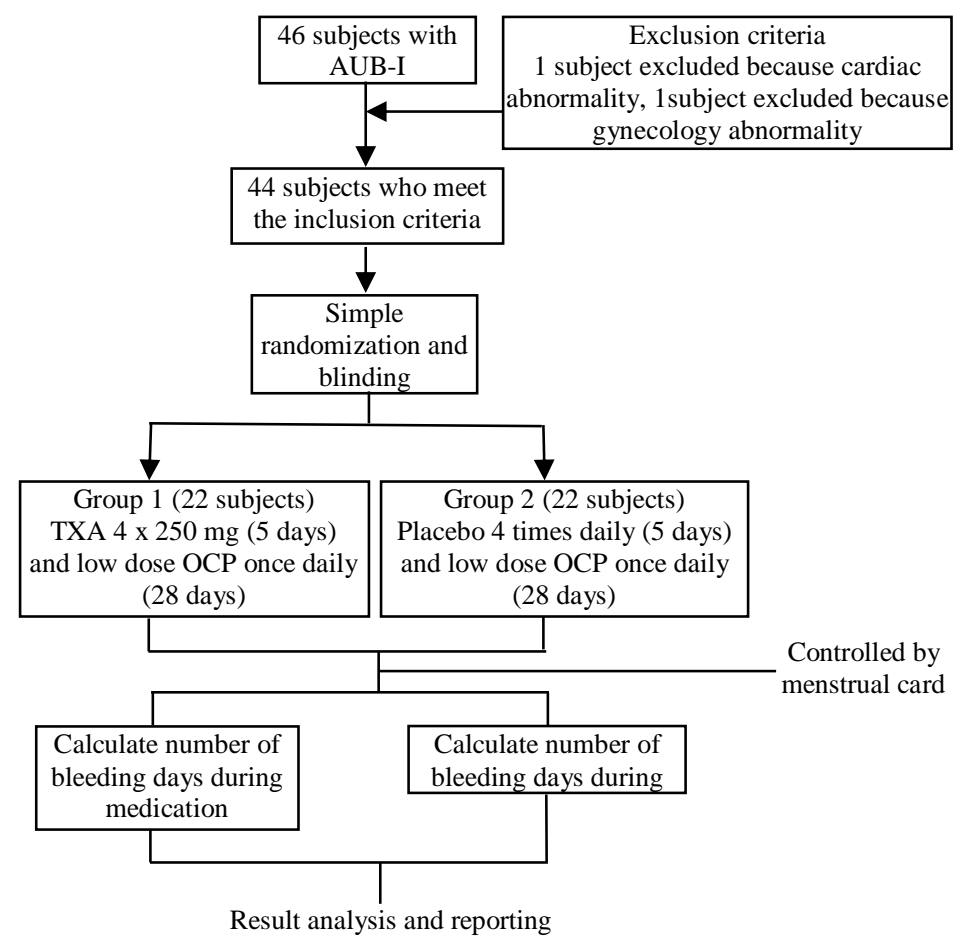

Figure 1. Consort diagram

The mean bleeding length during the treatment was significantly different between Group 1 and Group 2 which is $5.2 \pm 3.62$ days (1-11 days) and 9.2 \pm 6.16 days (2-23 days), respectively ( $\mathrm{p}=0.018)$. The subjects given TXA and OCP had shorter bleeding days during treatment significantly compared with given OCP pills only as shown in figure 2 .

Table 1. Characteristics of subjects in both groups

\begin{tabular}{|c|c|c|c|}
\hline \multirow{2}{*}{ Characteristics } & \multicolumn{2}{|c|}{ Group } & \multirow[b]{2}{*}{$\mathbf{P}$} \\
\hline & $\begin{array}{l}\text { Group 1 } \\
(\mathrm{n}=\mathbf{2 2})\end{array}$ & $\begin{array}{c}\text { Group } 2 \\
(n=22)\end{array}$ & \\
\hline Age & 31 & 26 & $0.086^{\mathrm{a}}$ \\
\hline $\begin{array}{l}\text { Body Mass } \\
\text { Index }\end{array}$ & 19.92 & 20.59 & $0.716^{\mathrm{a}}$ \\
\hline $\begin{array}{l}\text { Number of } \\
\text { previous } \\
\text { pregnancies }\end{array}$ & & & $0.067^{\mathrm{b}}$ \\
\hline $1(\mathrm{n}(\%))$ & $7(31.8)$ & $15(68.2)$ & \\
\hline $2(\mathrm{n}(\%))$ & $11(50)$ & $5(22.7)$ & \\
\hline $3(\mathrm{n}(\%))$ & $2(9.1)$ & $2(9.1)$ & \\
\hline $4(\mathrm{n}(\%))$ & $2(9.1)$ & $0(0)$ & \\
\hline
\end{tabular}

$\mathrm{SD}=$ Standard Deviation

a) Mann Whitney; b) $\chi^{2}$

The percentage of subjects in whom bleeding was stopped during the first week after initial treatment was significantly higher in group 1 than group $2(77.3 \% \mathrm{VS}$ $45.5 \%, \mathrm{p}<0.050)$.

The side effects reported in this study were dizziness and nausea. Table 2 showed that five subjects in Group 1 experienced the side effects, while only one subject in Group 2 experience them. The side effects were not significantly different between both groups $(p=0.185)$.

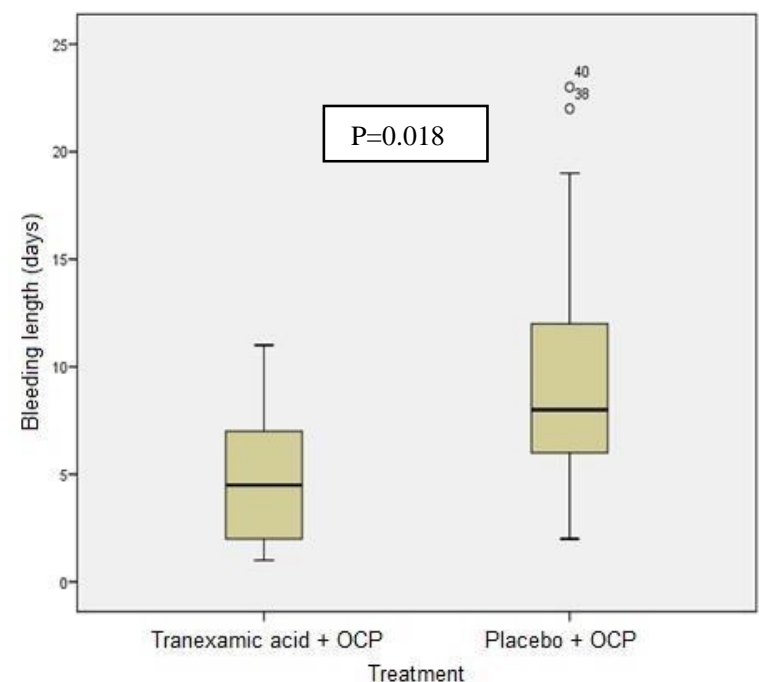

Figure 2. Bleeding length box plot between the two groups

Table 2. Side Effect in both groups

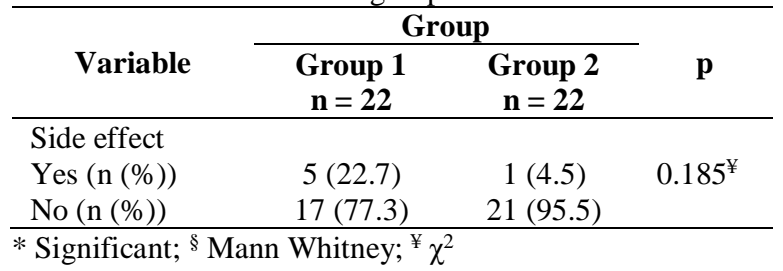

\section{DISCUSSION}

From our study result, we found that the mean bleeding length was $5.2 \pm 3.62$ days and $9.2 \pm 6.16$ days in groups 1 (TXA and low dose OCP) and 2 (OCP only) respectively. These bleeding lengths were significantly different between both groups $(\mathrm{p}=0.018)$. The percentage of subjects in whom bleeding was stopped during the first week after initial treatment was significantly higher in group 1 than group $2(77.3 \% \mathrm{VS}$ $45.5 \%, \mathrm{p}<0.050)$. 
In our study, the bleeding length was shorter significantly in Group 1 (TXA and low dose OCP). Several studies showed similar results that the use of TXA would shorten the bleeding length, especially for irregular bleeding. Senthong and Taneepanichskul found significant effect of TXA on AUB in DMPA users with the same dose, $250 \mathrm{mg}$ TXA, four times a day for 5 days. ${ }^{16}$ Phupong et al. found a significant effect of the antifibrinolytic drugs in Norplant users who experienced irregular bleeding. The dose of TXA was $500 \mathrm{mg}$, twice a day, for 5 days. The bleeding length was found to stop in less than 7 days in the treatment group. ${ }^{17}$ Senthong et al also found a similar result when studying the effect of TXA in DMPA users compared with the placebo. In their study, the bleeding length of less than 1 week was found significantly higher in the treatment group ( $88 \%$ vs $8.2 \%)$. The mean of days without bleeding was also higher in treatment group (20.6 days) than the control group (7.5) days. In this study, the percentage of subjects in whom bleeding was stopped during the first week after initial treatment was significantly higher in the group treated with TXA and OCP than OCP only (77.3\% VS $45.5 \%, \mathrm{p}<0.050) .{ }^{16}$

Mechanism of action of TXA is blocking lysin, the binding site of plasminogen reversibly, leading to inhibition of interaction between plasmin and fibrin polymer. Afterwards, TXA will reduce fibrin degradation, stabilize blood clot and reduce bleeding. Therefore, TXA acts effectively as a treatment for irregular bleeding caused by DMPA who had irregular bleeding due to hemostatic disturbance. ${ }^{17,14}$ The fibrinolytic enzymes in the endometrial layer have a significant role in the homeostasis of menstrual bleeding. In dysfunctional bleeding, the activity of plasmin and plasminogen activator increases due to an increase of fibrinolysis. TXA will exert its antifibrinolytic effects and reduce hypermenorrhea up to $50 \%$. $^{1}$ The mild side effects, such as dizziness and nausea, were experienced by five subjects in Group 1 (TXA and OCP) and one subject in group 2 (OCP only). Similar side effects were experienced by subjects treated with TXA in the study by Senthong et al. ${ }^{16}$

Risk factors, such as age, number of previous pregnancies, and BMI, were not significantly different between Group 1 and Group 2. Therefore, the bleeding length in both groups was not affected by those risk factors. ${ }^{18,19}$ Similar result was shown by Senthong et al., with mean age of 27 and 29 years old in treatment and control group, respectively. Furthermore, they also found no significant effect of BMI and the number of previous pregnancies on the bleeding length. ${ }^{20}$

Limitations of this study were the short duration of the study and no data on hormonal levels, which are supposed to affect the bleeding length. Statistical analysis of the bleeding length before the treatment was also not performed. In conclusion, this study resulted in the reduction of bleeding length in DMPA users with administration of TXA. Further studies should be conducted with a longer duration (follow-up in 3 months).

\section{CONCLUSIONS}

The administration of TXA $250 \mathrm{mg}$ four times daily for five days significantly reduces the bleeding length in DMPA users with AUB who use OCP. TXA can be used as alternative therapy to enhance the OCP effectivity for AUB due to DMPA.

\section{ACKNOWLEDGEMENTS}

We would like to show our gratitude to our patients, for their trust and support to this study, to dr. Kariadi Hospital, Semarang, Indonesia, and to midwives that greatly assisted the research.

\section{REFERENCES}

1. Azima, S. \& Roozbeh, N. Comparing the Effects of Tranexamic Acid and Mefenamic Acid in IUDinduced Menorrhagia : Randomized Controlled Trial. Int. J. Community Based Nurs. Midwifery1, 216-23 (2013).

2. Briefing, I. \& Urban, S. From MDGs to SDGs : What are the Sustainable Development Goals? What came of the UN Sustainable. 1-4 (2015).

3. Novak E. Berek \& Novak's gynecology:Lippincott Williams \& Wilkins; 2007.

4. Schrager, S. Abnormal uterine bleeding associated with hormonal contraception. Am. Fam. Physician65, 2073-80 (2002).

5. HIFERI. Konsensus Tatalaksana Pendarahan Uterus Abnormal karena Efek Samping Kontrasepsi. (2013).

6. Kamalifard, M., Sadeghi-bazargani, H. \& Mohammad-alizadeh, S. Comparison of Continuation Rates and Reasons of Discontinuation for Cyclofem and Depot - medroxyprogesterone acetate in Rural Areas of East Azerbaijan Province , Iran. (2012).

7. Munro, M. G., Critchley, H. O. D., Fraser, I. S. \& Menstrual, F. The two FIGO systems for normal and abnormal uterine bleeding symptoms and classification of causes of abnormal uterine bleeding in the reproductive years : 2018 revisions. 393-408 (2018).

8. Sereepapong, W. et al. Endometrial progesterone and estrogen receptors and bleeding disturbances in depot medroxyprogesterone acetate users. (2004).

9. Vincent, A. J. \& Salamonsen, L. A. The role of matrix metalloproteinases and leukocytes in abnormal uterine bleeding associated with progestin- only contraceptives. 15, 135-143 (2000).

10.Rogers, P. A. W., Affandi, B. \& Kovacs, G. Decreased tissue inhibitor of metalloproteinase in the endometrium of women using depot medroxyprogesterone acetate: a role for altered endometrial matrix metalloproteinase / tissue inhibitor of metalloproteinase balance in the pathogenesis of abnormal uterine bleeding. Hum Reprod. 2002; 17 (5) : 1189-98.

11.Abdel-Aleem H, d'Arcangues C, Vogelsong KM, Gaffield ML, Gülmezoglu AM. Treatment of vaginal bleeding irregularities induced by progestin only contraceptives. Cochrane Database of Systematic Reviews 2013, Issue 10. Art. No.: CD003449.

12. Arcangues, C. Management of vaginal bleeding irregularities induced by progestin-only contraceptives. 15, 24-29 (2000). 
13. Shabaan, M. M., Zakherah, M. S., El-nashar, S. A. \& Sayed, G. H. Levonorgestrel-releasing intrauterine system compared to low dose combined oral contraceptive pills for idiopathic menorrhagia: a randomized clinical trial. Contraception 83 , 48-54 (2011).

14. Maybin, J. A. \& Critchley, H. O. Medical management of heavy menstrual bleeding. Women's Heal.12, 27-34 (2016).

15. McCormack, P. L. Tranexamic Acid: A review of its use in the treatment of hyperfibrinolysis. Drugs 72 , 585-617 (2012).

16.Ssenthong AJ, T. The effect of tranexamic acid for treatment irregular uterine bleeding secondary to DMPA use. J Med Assoc Thai4, 461-5 (2009).
17.Phupong, V., Sophonsritsuk, A. \& Taneepanichskul, S. The effect of tranexamic acid for treatment of irregular uterine bleeding secondary to Norplant ${ }^{\circledR}$ use. Contraception73, 253-256 (2006).

18. Chaudhri, R., Rizvi, F. \& Afzal, M. Body weight and bleeding pattern changes in women using DMPA-SC. J. Coll. Physicians Surg. Pakistan19, 618-621 (2009).

19. Connor, P. D., Tavernier, L. A., Thomas, S. M., Gates, D. \& Lytton, S. M. Determining Risk Between Depo-Provera Use and Increased Uterine Bleeding in Obese and Overweight Women. 7-10 (2001).

20. Arab, N. Health Approach in the control of Irregular Bleeding due to Depomedroxy Progesterone Acetate. J Res Heal. Sci5, 32-6 (2005). 